\title{
Do psychosocial work factors and social relations exert independent effects on sickness absence? A six year prospective study of the GAZEL cohort
}

\author{
M Melchior, I Niedhammer, L F Berkman, M Goldberg
}

See end of article for authors' affiliations

\section{Correspondence to:}

Maria Melchior, INSERM

Unit 88, Hôpital National

de Saint-Maurice, 14 rue

du Val d'Osne, F-94415

Saint-Maurice Cedex,

France;

mmelchio@hsph.harvard.edu

Accepted for publication 11 September 2002

\begin{abstract}
Study objectives: The objective of this prospective cohort study was to determine whether psychosocial work characteristics and social relations exert independent effects on the incidence of sickness absence in a population of middle aged French employees over six years of follow up.

Design: This study included 9631 men and 3595 women participating in the French GAZEL cohort. Social relations (social networks, personal social support, and social relations satisfaction) were measured in 1994 by self report. Psychosocial work characteristics (decision latitude, psychological demands, and social support at work) were ascertained in 1995. Sickness absence data were collected independently. The authors studied the incidence of short (>7 days), intermediate (7-21 days), and long (>21 days) spells of absence from 1995 to 31 December 2001. Rate ratios associated with psychosocial exposures, adjusted on sociodemographic characteristics, and health behaviours, were calculated by means of log-linear Poisson regression.

Setting: A cohort of 20000 employees of France's national gas and electricity company (the GAZEL study).

Main results: Among men and women, levels of decision latitude and personal social support below the median predicted $17 \%$ to $24 \%$ increases in absence rates. Low satisfaction with social relations and low social support at work lead to a $10 \%$ to $26 \%$ excess in sick leaves among men. No interactive effects were found between the variables under study.

Conclusions: The quality of the work environment and of social relations affect sickness absence over an extended period of follow up. This study supports the hypothesis of independent, not interactive effects.
\end{abstract}

S ickness absence, a general indicator of health status, ${ }^{12}$ is a reflection of disease. On an individual level, it is also determined by an individual occupational status, ${ }^{34}$ family circumstances, ${ }^{5}$ and sociocultural characteristics. ${ }^{6}$ Collectively sickness absence rates are associated with workplace organisation, ${ }^{7-9}$ social policy (for example, sick leave benefits), ${ }^{10}$ labour market characteristics, ${ }^{11}$ and the local sickness absence culture. ${ }^{12}$ Sickness leave is also a socioeconomic indicator, relevant for employers. ${ }^{13}$ While short spells are thought to be most affeced by social and occupational factors, long absences are reliable indicators of health status. ${ }^{14}$

Psychosocial work conditions predict the occurrence of cardiovascular ${ }^{15}$ and musculoskeletal ${ }^{16}{ }^{17}$ disease, and are associated with sick leave independently of occupational status. In particular, controlling for professional grade, a lack of control over the content, and the execution of job related tasks, ${ }_{11}^{12}{ }^{12-20}$ high job demands, ${ }^{12}{ }^{17}$ and low social support at work $^{12151721}$ are directly related to more frequent sickness absence spells. According to the job strain and the iso-strain models, these factors exert interactive health effects; with regard to sickness absence this hypothesis is partly substantiated..$^{12}$ The health impact of job stress factors may be mediated by psychological wellbeing, ${ }^{22}{ }^{23}$ physiological arousal, $^{24}$ and risk behaviours (for example, cigarette smoking, ${ }^{25}{ }^{26}$ excessive alcohol consumption). ${ }^{27}{ }^{28}$ In addition, sickness absence may also be a "coping behaviour" ${ }^{\prime 3}$ in face of stressful work conditions and is likely to reflect "work commitment or pressure to attend work."29 30

The extent and quality of social relations are independently related to morbidity and mortality. ${ }^{31}{ }^{32}$ As a stressful exposure, poor social relations affect psychological and physical wellbeing $^{31}$ and constitute a risk factor for sickness absence. ${ }^{33}$ However, the availability of social support may also encourage illness behaviour and increase the occurrence of sickness absence spells. ${ }^{34}$ It may be that different aspects of social relations exert distinct health effects. Furthermore, the impact of social relations may be moderated by other factors such as gender and social class.

Psychosocial exposures in the workplace and at home could constitute one of the mechanisms responsible for social health inequalities, with different effects for men and women. ${ }^{35} 3738$ Few studies have examined the health effects of these factors simultaneously. In the Whitehall II study negative aspects of social relations were found to predict health functioning and psychological wellbeing, an effect that was moderated by social support received at work. ${ }^{22}{ }^{34}$ Another report from the same study population showed that low control at home and at work were independently associated with the occurrence of depression and anxiety. ${ }^{35}$ With regard to sickness absence there is evidence that psychosocial work factors are stronger predictors than personal social support ${ }^{36}$ and that there are interactive effects between different job characteristics. ${ }^{12}$

Previous reports from the GAZEL cohort, a prospective study of middle aged French men and women, showed that psychosocial work factors are associated with occupational status and predict the one year incidence of sickness absence $^{19}$ and that social relations are directly associated with health status. ${ }^{39}$ The purpose of this study was to test whether psychosocial factors at work and social relations exert independent effects on all cause sickness absence among men and women over a six year period of follow up. 


\section{METHODS}

\section{Study population}

In 1989, all men between the ages of 40 to 50 and women 35 to 50 employed by France's national gas and electricity company, Electricité de France-Gaz de France (EDF-GDF), were solicited to participate in the GAZEL study ${ }^{40}{ }^{41}$ Women, who represent only $20 \%$ of the company employees, were oversampled to ensure their adequate representation in the study population. The 20624 subjects who accepted (44.7\%) are followed up yearly, via a self administered questionnaire. In parallel, data on their occupational status, sickness absence, and health are collected directly by the human resources and medical departments at EDF-GDF.

In 1995, 18037 GAZEL participants were in the work force (222 died and 2365 retired). Of those, $72 \%(n=13226 ; 9631$ men and 395 women) returned the self administered questionnaire. To investigate the possibility of a response bias we compared their baseline characteristics with people who were still employed in 1995 but did not return the self administered questionnaire. Compared with respondents, nonrespondents were more likely to be female (respectively $27.3 \%$ and $29.3 \%, p=0.0082$ ), to smoke cigarettes (respectively $25.5 \%$ and $35.4 \%, \mathrm{p}>0.0001$ ), to experience poor health (respectively $11.3 \%$ and $15.8 \%, \mathrm{p}<0.0001$ ), and to declare chronic illnesses (respectively on average 1.89 and 2.02, p<0.0001). Most participants who did not answer the 1994 questionnaire also failed to return the 1995 survey (76.7\%). Respondents who did not return the 1994 questionnaire were similar, in terms of sociodemographic and health characteristics, to 1995 nonrespondents.

With regard to the outcome, sickness absence, participants accrued person time at risk from the day on which they returned the 1995 questionnaire until 31 December 2000. The participants who retired $(n=7090)$, died $(n=165)$, or asked to withdraw from the study $(n=11)$ during the six year period of follow up contributed to the accumulation of person time until the date of their retirement, death, or withdrawal. We then subtracted all sickness absences from the time at risk. ${ }^{42}$ Overall 41413 person years of observation were accrued among men and 17256 among women, with an average duration of follow up, respectively, of 4.3 and 4.8 years.

\section{Measures of psychosocial work factors}

In 1995, GAZEL participants completed assessments of psychosocial characteristics of their work, based on questionnaires developed by Karasek ${ }^{43}$ and Johnson. ${ }^{44}$ Three summary measures were derived from these data: decision latitude (six items measuring the influence over the content and the execution of work related tasks), psychological demands (five items regarding job demands, time pressures and conflicting demands), and social support at work (five items on the quality of contacts with coworkers during and outside work). The psychometric properties of the three scales have previously been described. ${ }^{45}$ The measures show factorial validity and internal consistency reliability with the following Cronbach's $\alpha$ coefficients: decision latitude: 0.65 , psychological demands: 0.69 , social support at work: 0.52 . To compare exposed and non-exposed individuals we created binary indicator variables by dichotomising the distribution of each of the three summary scales at its median value.

\section{Measures of social relations}

Our measures of social relations, obtained through the 1994 self administered questionnaire that included 33 items adapted from the New Haven EPESE study ${ }^{46}$ and translated to French, has been described elsewhere. ${ }^{39}$ Briefly, social networks included: (1): items concerning social contacts with children living outside the household (five items), parents and in laws (five items), other family members (three items), and friends (three items), (2): an indicator of membership in voluntary organisations (six items), and (3): the presence of a spouse/partner (one item). We summed the four types of social contacts (children, parents/in laws, other family and friends) giving an equal weight to family and non-family ties and divided the distribution into quartiles. Particpants in the bottom quartile were assigned a score of 0 , those in the second quartile 1 , in the third 2, and in the top 3. To measure group affiliation we assigned scores of voluntary group membership: 0 (none), 1 (one), 2 (two), and 3 (three or more). Marital status was coded 3 for participants who were married or living with a partner, 0 for others. We summed social contacts, group affiliation and marital status to obtain a social network index (SNI) ranging from 0 to 9 . The predictive validity of this indicator has been demonstrated in previous studies of mortality and morbidity. ${ }^{46-48}$ Its internal consistency reliability was not tested (it is not a scale but a summary measure). To study the health impact of social integration we used four levels of social networks: "poor networks" ( score of 0-2), "average networks" (3-4), "fair networks" (5-6), and "extended networks" (7-9).

Our indicator of personal social support was a sum of four items assessing emotional and instrumental help. The measure of social relations satisfaction was based on six items regarding the perceived quality of relations with family and friends. The construct validity of the two scales was empirically confirmed by a factor analysis with an orthogonal Varimax rotation. Cronbach's $\alpha$ coefficients were: social support: 0.66 , social relations satisfaction: 0.53 . To facilitate the interpretability of the measures in all statistical analyses we constructed binary indicators by dichotomising their distribution at the median value.

\section{Sickness absence data}

EDF-GDF is a state owned company of over 100000 employees that produces and distributes electricity and gas. Its employees benefit from a particular, company based, social insurance system that covers all of the income lost during a medically motivated absence from work. Any sickness absence spell, regardless of its duration, has to be certified by a physician. The motive of absence is confirmed by a medical doctor employed by the EDF-GDF social insurance department, which permits the independent verification of the reason and duration of all sick absence spells. Maternity leaves did not occur in our middle aged study population. In France employees caring for sick children benefit from a specific type of family leave, guaranteed by national legislation.

At EDF-GDF the information on the date, length, and medical cause of each occurrence of sickness absence is managed by the medical department. For the GAZEL participants these data are updated yearly. We chose to study the occurrence of three categories of sickness absence: 1-7 days (short), 8-21 days (intermediate), and >21 days (long) spells. This classification accounts for the fact that the determinants of short and long spells differ ${ }^{49}$ and is similar to the one used in the Whitehall II study, ${ }^{50}$ which permits the comparison of our results.

\section{Covariates}

Participants' demographic, occupational, and behavioural characteristics were assessed in the self administered questionnaire of 1995. Age was divided into three categories for men $(45-49,50-54$, or 55-56) and four for women (42-44, 45-49, 50-54, or 55-56). We collapsed marital status into three groups: single, married/living with a partner or divorced/ separated/widowed. Educational attainment was divided into six categories reflecting degrees obtained (primary, lower vocational, lower secondary, higher secondary, higher vocational, and university). Occupational status was grouped into six classes (workers, clerks, foremen/technicians, administrative associate professionals, engineers, and managers). We defined smoking as the consumption of at least one cigarette per day and categorised alcohol consumption into four groups: 
light drinkers ( $1-13$ drinks/week for men; 1-6 drinks/week for women), intermediate drinkers (14-27 drinks/week for men; 7-20 drinks/week for women), heavy drinkers ( $\geqslant 28$ drinks/ week for men; $\geqslant 21$ drinks/week for women), and nondrinkers. Participants' body mass index (BMI) was calculated by dividing their weight $(\mathrm{kg})$ by their height $\left(\mathrm{m}^{2}\right)$; we considered individuals whose BMI exceeded $28 \mathrm{~kg} / \mathrm{m}^{2}$ to be overweight. In complementary analyses we adjusted on self reported health (measured by one item: "How do you judge your overall health status?" rated on an 8 point scale) and self reported frequent depressive symptoms (in the prior 12 months).

\section{Statistical analysis}

Sickness absence being a form of count data, we fitted log-linear Poisson regression models to compute the rate of each type of sickness absence spell per 100 person years of observation. The full details of the statistical method used have previously been published..$^{18}$ Briefly, for the $\mathrm{i}^{\text {th }}$ observation, we used the following regression model:

$$
\log \left(\mu_{i}\right)=\log \left(\mathrm{T}_{i}\right)+\alpha+\sum_{j=1}^{p} \beta_{j} x_{i j}
$$

where $i=1, \ldots, n ; \mu_{i}$ is the number of spells of absence. $\mathrm{T}_{i}$ is the number of years of follow up, and $x_{i 1}, \ldots, x_{i p}$ are the explanatory variables.

We accounted for the overdispersion of the data by estimating a scale parameter obtained by dividing the residual deviance by the number of degrees of freedom.

We studied the association of each of the explanatory variables of interest with short, intermediate, and long spells of sickness absence in three stages. Firstly, we calculated age adjusted rate ratios. Secondly, we adjusted each regression model for marital status, educational level, occupational status, smoking, alcohol consumption, and overweight (the regression model fitted to evaluate the impact of social networks was not adjusted for marital status). We found no relation between social networks and sickness absence and tested the predictive power of each of the six types of social contacts to ensure that our summary measure did not suffer from a lack of sensitivity. Thirdly, we simultaneously studied all the explanatory variables of interest, adjusting for all potential confounders. To ensure that baseline health status did not confound the relations observed, we verified that the results were stable controlling for self rated health and depressive symptoms (results not shown). Throughout, we studied men and women separately.

We tested two way interactions between decision latitude, psychological demands, and social support at work, as well as between the three psychosocial work factors and social relations variables, firstly as dichotomous indicators, secondly divided into quartiles, in relation to the overall number of spells of sickness absence. In stratified analyses we investigated whether the impact of psychosocial exposures varies with occupational status.

All the statistical analyses were performed using the SAS statistical software package. ${ }^{51}$ To fit log-linear Poisson regression models we used the PROC GENMOD procedure.

\section{RESULTS}

During the period of follow up men had 21028 spells of sickness absence ( 11671 short, 5614 intermediate, and 3736 long spells), women 17805 (10 433 short, 4667 intermediate, and 2697 long spells). On average, there were 51 spells of absence per 100 years of observation ( 28 short, 14 intermediate, and 9 long) among men, while women experienced 103 spells per 100 person years (respectively 60 short, 27 intermediate, and
16 long spells). Thus, for short and intermediate absences, the rates of absence among women were two times higher than among men. The leading causes of absence were musculoskeletal problems (about 15\% of spells), psychiatric disorders, and respiratory illnesses (each accounting for about $11 \%$ of spells).

In our study sample, men were older, more likely to be married, to hold a high occupational position, and to report smoking, heavy alcohol consumption, and being overweight. Women were more likely to declare poor health and to suffer from frequent depressive symptoms (table 1). As shown in table 2, for men and women, the exposure to low decision latitude was inversely related to occupational status. The prevalence of low social support at work was highest among participants employed as clerks. Among men, we found an inverse relation between social networks and occupational grade, but a direct association between occupation and the personal social support or social relations satisfaction: male managers were most likely to be isolated but reported more personal social support and a greater satisfaction with social contacts. Overall, women experienced worse psychosocial conditions both at work and in the personal sphere than men.

The age adjusted rates of sickness absence among men exposed to low decision latitude were 57\% (for long spells) to $75 \%$ (for intermediate spells) higher than among men with high decision latitude (table 3). Among women corresponding rate ratios were smaller ( $30 \%$ increase in short and long spells, $38 \%$ increase in intermediate spells). Controlling for potential confounders, particularly occupational status, reduced this effect by $30 \%$ among men and $20 \%$ among women, yet low decision latitude remained a significant risk factor. For men, low social support at work was a significant predictor, regardless of the length of the sickness absence spell and independently of other risk factors. Among women low social support at work and high demands were related to incresed rates of short spells.

Table 4 shows rate ratios of sickness absence in relation to social relations variables. Poor social networks did not significantly predict sickness absense. In complementary analyses, we found that in comparison with married individuals, divorcees had an increased rate of sickness absence, while single women were less susceptible of missing work for health reasons. No relations between the other structural domains of social networks and absenteeism were identified (results not shown). Poor social support and low satisfaction with social relations respectively predicted a $10 \%-30 \%$ increase in the incidence of all types of sickness absence among men and women.

In multivariate analyses (table 5) decision latitude and personal social support were the strongest predictors of sickness absence. Low decision latitude increased the rates of absences by $18 \%-24 \%$ among men, and those of short and intermediate spells among women (respectively $12 \%$ and $20 \%$ ). A lack of personal social support was associated with an increase in short and intermediate absences among men and women (respectively $22 \%$ and $13 \%-35 \%$ ) and an excess of long spells among men $(23 \%)$. Social support at work and dissatisfaction with social relations predicted sickness absence only among men. High psychological demands predicted incident short spells among women only. Socially isolated men and women had increased rates of long spells of sickness absence, but these results did not reach statistical significance. Among women, none of the psychosocial exposures under study were associated with long spells of absence.

We found no evidence of confounding between work and personal psychosocial characteristics. In addition, there were no significant interactions between decision latitude, psychological demands and social support at work, or between psychosocial work factors and social relations variables. We found no effect modification by occupational status. 


\begin{tabular}{|c|c|c|c|c|}
\hline \multirow[b]{2}{*}{ Variable } & \multicolumn{2}{|c|}{ Men $(n=9631)$} & \multicolumn{2}{|c|}{ Women $(n=3595)$} \\
\hline & $\%$ & $\mathrm{~N}$ & $\%$ & $\mathrm{~N}$ \\
\hline \multicolumn{5}{|l|}{ Age } \\
\hline $42-44$ & - & - & 24.5 & 880 \\
\hline $45-49$ & 44.4 & 4277 & 43.2 & 1555 \\
\hline $50-54$ & 47.3 & 4557 & 26.3 & 945 \\
\hline $55-56$ & 8.3 & 798 & 6.0 & 216 \\
\hline \multicolumn{5}{|l|}{ Marital status } \\
\hline Single & 2.1 & 197 & 6.7 & 242 \\
\hline Divorced/widowed & 5.5 & 531 & 18.3 & 656 \\
\hline Married/cohabitating & 92.4 & 8894 & 75.0 & 2696 \\
\hline \multicolumn{5}{|l|}{ Educational level } \\
\hline Primary & 4.8 & 465 & 6.2 & 222 \\
\hline Lower vocational & 12.6 & 1212 & 19.1 & 686 \\
\hline Lower secondary & 51.3 & 4942 & 49.0 & 1761 \\
\hline Higher vocational & 6.5 & 625 & 11.5 & 413 \\
\hline Higher secondary & 7.0 & 673 & 5.6 & 200 \\
\hline University & 17.8 & 1713 & 8.7 & 314 \\
\hline \multicolumn{5}{|l|}{ Occupational status } \\
\hline Workers & 7.8 & 746 & - & - \\
\hline Clerks & 2.8 & 269 & 19.4 & 694 \\
\hline Foremen/technicians & 36.8 & 3535 & 10.4 & 372 \\
\hline Administrative associate professionals & 12.6 & 1204 & 58.2 & 2085 \\
\hline Engineers & 22.7 & 2177 & 5.0 & 178 \\
\hline Managers & 17.4 & 1666 & 7.1 & 253 \\
\hline \multicolumn{5}{|l|}{ Children } \\
\hline 0 & 27.0 & 1802 & 27.2 & 666 \\
\hline 1 or more & 73.0 & 7830 & 72.8 & 2930 \\
\hline \multicolumn{5}{|l|}{ Self reported health status } \\
\hline Good & 77.4 & 7450 & 71.3 & 2564 \\
\hline Poor & 22.6 & 2182 & 28.7 & 1032 \\
\hline \multicolumn{5}{|l|}{ Frequent depressive symptoms } \\
\hline Ábsent & 94.9 & 9142 & 83.4 & 2998 \\
\hline Present & 5.1 & 490 & 16.6 & 598 \\
\hline \multicolumn{5}{|l|}{ Smoking } \\
\hline No & 79.1 & 7579 & 83.9 & 2987 \\
\hline Yes & 20.9 & 2002 & 16.1 & 572 \\
\hline \multicolumn{5}{|l|}{ Alcohol consumption } \\
\hline Non-drinker & 8.8 & 755 & 27.2 & 825 \\
\hline Light drinker & 53.0 & 1996 & 49.2 & 1496 \\
\hline Moderate drinker & 23.3 & 4541 & 19.8 & 602 \\
\hline Heavy drinker & 14.8 & 1269 & 3.8 & 115 \\
\hline \multicolumn{5}{|l|}{ Overweight } \\
\hline No & 72.1 & 6947 & 87.5 & 3148 \\
\hline Yes & 27.9 & 2685 & 12.5 & 448 \\
\hline
\end{tabular}

\section{DISCUSSION}

\section{Findings}

This six year prospective study demonstrates that decision latitude, social support, and social relations satisfaction predict the incidence of sickness absence over a six year period of follow up. Psychosocial work factors and social relations were shown to exert independent effects on sickness absence. With the exception of the association between decision latitude and occupational status, the variables under study were not confounded by demographic, behavioural, or health characteristics.

\section{Sickness absence as a measure of health status}

Although sickness absence is a multidimensional phenomenon influenced by attitudinal and social factors, its validity as a general health measure should not be underestimated. ${ }^{14}$ Among existing measures of absenteeism, we chose to calculate the incidence rates of three lengths of all cause sickness absence. ${ }^{42}$ This indicator was appropriate given the extended follow up in our study: we were able to model recurrent episodes of sickness absence and to account for variations in the time at risk in the study population. One of the possible limitations of the incidence rate in the precision of the definition of the population at risk. ${ }^{42}$ In this study time at risk was accrued by individuals employed by a single company whose exact dates of cohort entry and exit (whether because of retirement, death, or withdrawal) were available. Furthermore, we subtracted the duration of all sickness absence spells from the period of follow up, increasing its precision. Another issue relates to the assessment of the number of spells of absenteeism in the study population, which can be subject to random and systematic error. ${ }^{42}$ The incidence of sickness absence could be underestimated if participants with higher occupational status, likely to benefit from greater work flexibility, did not need to report all of their health related absences. We are unfortunately unable to determine the presence and impact of such bias in this study. Nevertheless, our use of data routinely collected by the medical department at EDF-GDF, which has previously been shown to be valid,$^{52}$ is an advantage over reports studying employees' self reported sick leaves as an outcome. ${ }^{14}$

\section{Psychosocial factors at work}

Our results concerning the impact of decision latitude and social support at work among men confirm the findings of Niedhammer et al in a 12 month prospective study in the same study population. ${ }^{19}$ While that study reported on the number of spells and the overall duration of sick leave, we evaluated the determinants of absences of short, intermediate, and long 


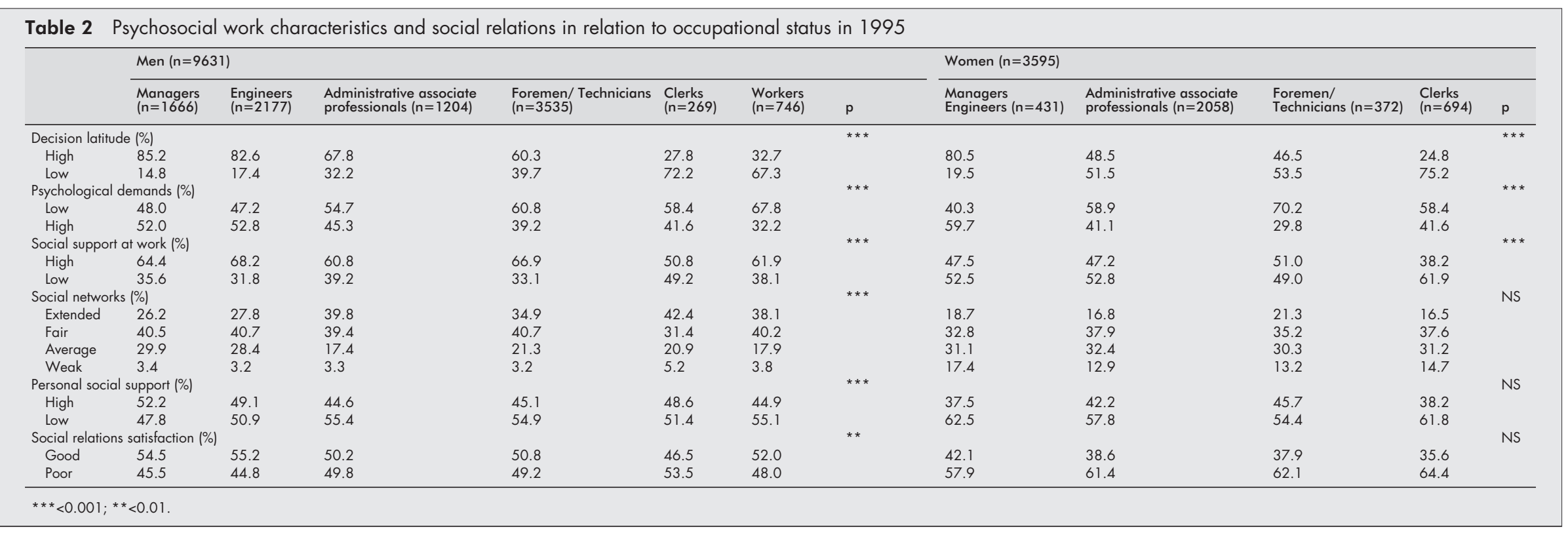

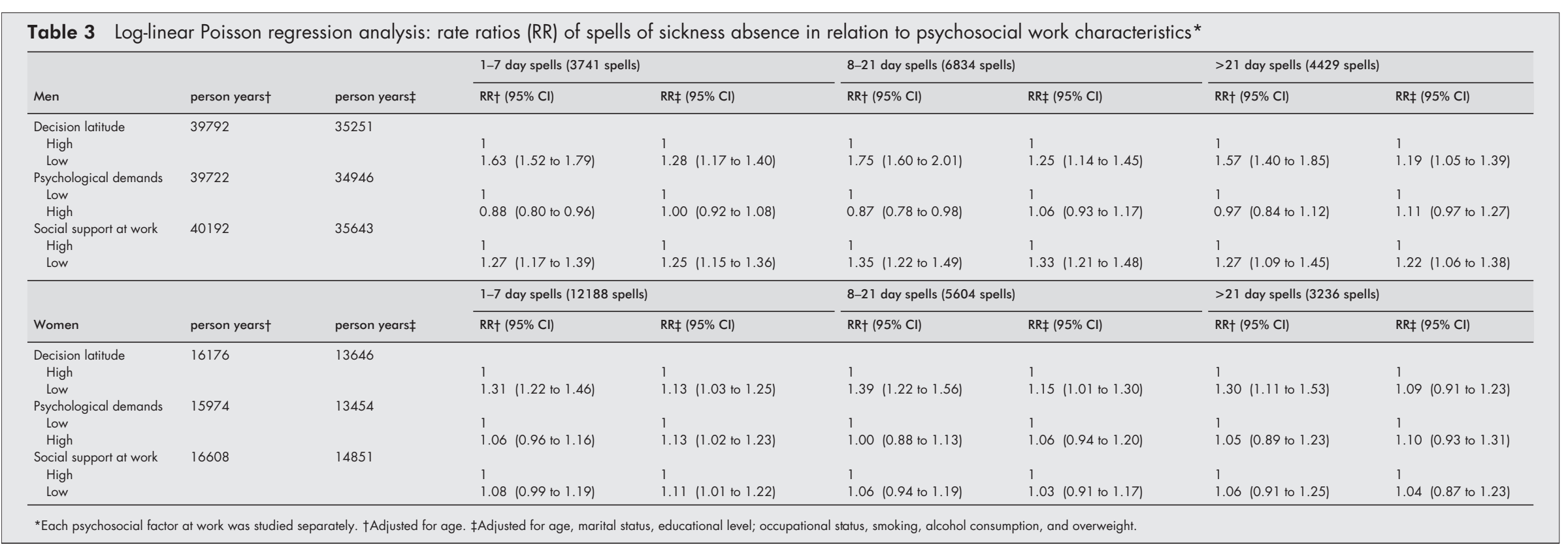


Table 4 Log-linear Poisson regression analysis: rate ratios (RR) of the incidence of sickness absence spells in relation to social factors in the GAZEL cohort *

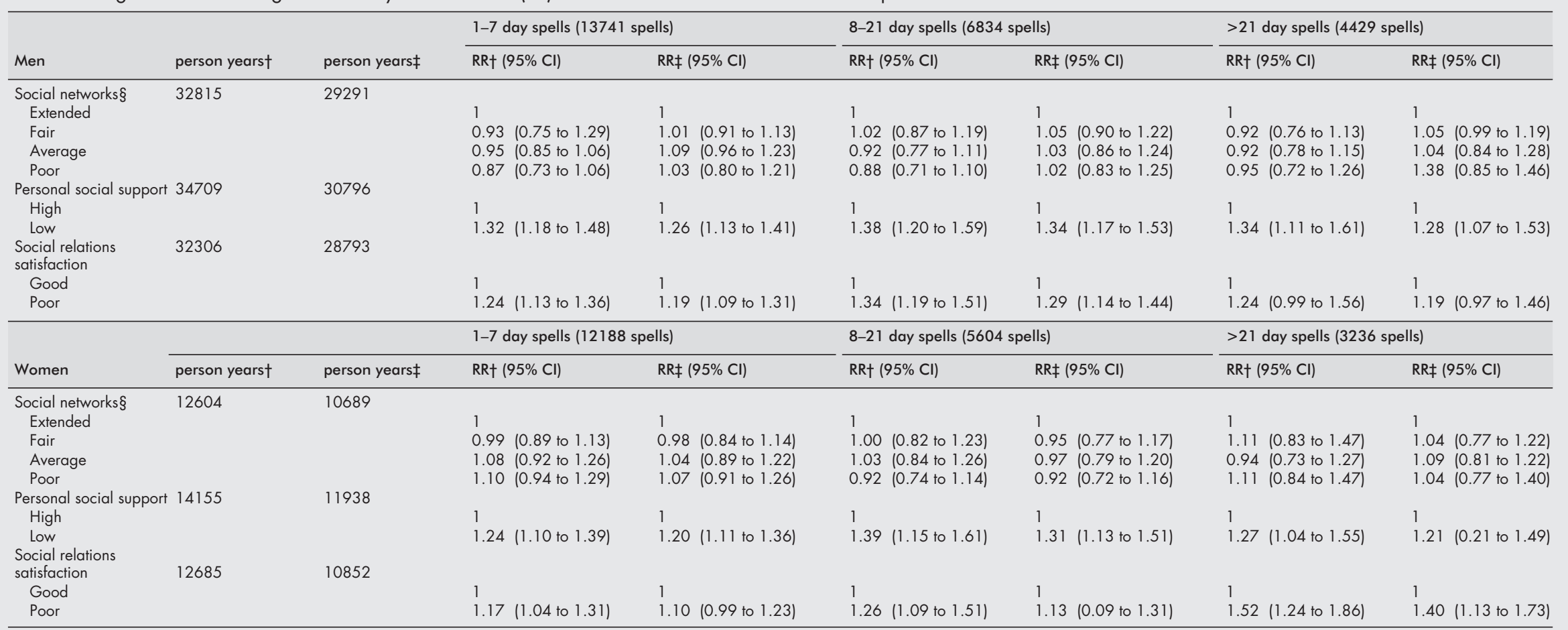

*Each social factor was studied separately. $†$ Adjusted for age. $\ddagger$ Adjusted for age, marital status, educational level; occupational status, smoking, alcohol consumption, and overweight. $\S$ The regression models studying the relation between the Social Networks Index and sickness absence were not adjusted on marital status. 
Table 5 Multivariate log-linear Poisson regression analysis: rate ratios (RR) of sickness absence spells in relation to psychosocial work characteristics and social factors*

\begin{tabular}{|c|c|c|c|c|c|c|}
\hline & \multicolumn{3}{|c|}{ Men (24882 person years) } & \multicolumn{3}{|c|}{ Women (8530 person years) } \\
\hline & $\begin{array}{l}1-7 \text { days } \\
\text { RR }(95 \% \mathrm{Cl})\end{array}$ & $\begin{array}{l}8-21 \text { days } \\
\text { RR }(95 \% \mathrm{Cl})\end{array}$ & $\begin{array}{l}>21 \text { days } \\
\operatorname{RR}(95 \% \mathrm{Cl})\end{array}$ & $\begin{array}{l}1-7 \text { days } \\
\text { RR }(95 \% \mathrm{Cl})\end{array}$ & $\begin{array}{l}8-21 \text { days } \\
\text { RR ( } 95 \% \mathrm{Cl})\end{array}$ & $\begin{array}{l}>21 \text { days } \\
\operatorname{RR}(95 \% \mathrm{Cl})\end{array}$ \\
\hline \multicolumn{7}{|c|}{ Decision latitude } \\
\hline High & 1 & 1 & 1 & 1 & 1 & 1 \\
\hline Low & 1.24 (1.13 to 1.37$)$ & 1.22 (1.08 to 1.37$)$ & 1.18 (1.00 to 1.40$)$ & $1.12(1.00$ to 1.26$)$ & $1.20(1.01$ to 1.40$)$ & $1.03(0.83$ to 1.27$)$ \\
\hline \multicolumn{7}{|c|}{ Psychological demands } \\
\hline Low & 1 & 1 & 1 & 1 & 1 & 1 \\
\hline High & 0.97 (0.88 to 1.08$)$ & $1.06(0.95$ to 1.19$)$ & 1.11 (0.94 to 1.32$)$ & $1.13(1.01$ to 1.26$)$ & $1.04(0.89$ to 1.27$)$ & $1.12(0.90$ to 1.39$)$ \\
\hline \multicolumn{7}{|c|}{ Social support at work } \\
\hline High & 1 & 1 & 1 & 1 & 1 & 1 \\
\hline Low & 1.18 (1.08 to 1.29 ) & 1.27 (1.13 to 1.42$)$ & $1.17(1.00$ to 1.38$)$ & $1.03(0.92$ to 1.16$)$ & $0.93(0.80$ to 1.09$)$ & $1.06(0.87$ to 1.30$)$ \\
\hline \multicolumn{7}{|c|}{ Social networks } \\
\hline Extended & 1 & 1 & 1 & 1 & 1 & 1 \\
\hline Fair & $0.99(0.88$ to 1.11$)$ & $0.99(0.84$ to 1.16$)$ & 0.97 (0.79 to 1.18$)$ & $0.95(0.80$ to 1.12$)$ & $0.99(0.71$ to 1.11$)$ & $0.98(0.71$ to 1.36$)$ \\
\hline Average & $1.02(0.89$ to 1.17$)$ & $0.92(0.75$ to 1.11$)$ & $0.94(0.74$ to 1.18$)$ & $1.05(0.96$ to 1.22$)$ & 0.91 (0.72 to 1.14 ) & $1.08(0.77$ to 1.51$)$ \\
\hline Poor & $0.86(0.80$ to 1.12$)$ & $0.93(0.76$ to 1.14$)$ & $1.05(0.79$ to 1.39$)$ & $1.02(0.83$ to 1.25$)$ & $0.86(0.65$ to 1.13$)$ & $0.98(0.71$ to 1.35$)$ \\
\hline \multicolumn{7}{|c|}{ Personal social support } \\
\hline High & 1 & 1 & 1 & 1 & 1 & 1 \\
\hline Low & $1.22(1.08$ to 1.38$)$ & $1.22(1.06$ to 1.42$)$ & $1.23(0.99$ to 1.50$)$ & 1.17 (1.02 to 1.35$)$ & 1.35 (1.12 to 1.62$)$ & $1.25(0.98$ to 1.60$)$ \\
\hline \multicolumn{7}{|c|}{ Social relations satisfaction } \\
\hline Good & 1 & 1 & 1 & 1 & 1 & 1 \\
\hline Poor & $1.14(1.03$ to 1.26$)$ & $1.21(1.08$ to 1.36$)$ & $1.13(0.95$ to 1.34$)$ & $1.04(0.91$ to 1.18$)$ & $1.00(0.84$ to 1.18$)$ & $1.39(1.09$ to 1.76$)$ \\
\hline
\end{tabular}

*All variables of interest were studied simultaneously, adjusting for age, educational level; occupational status, smoking, alcohol consumption, and overweight.

duration over an extended period of follow up. We confirmed that the effects of psychosocial work factors are comparable across the three lengths of absence ${ }^{153}$ and found that they are independent from social relations.

\section{Social relations}

In analyses adjusted on age we found that social isolation predicted a higher incidence of short and long absence spells among women. Studying simultaneously six indicators of the psychosocial environment at work and at home we found that a lack of personal social support or satisfaction with social relations, but not poor social networks, predicted sickness absence. Interestingly, in our study, members of lower occupational groups reported more extensive social networks. While a direct relation between socioeconomic status and social integration measured by networks has been suggested, ${ }^{54}{ }^{55}$ our findings are consistent with the hypothesis that members of lower status groups have stronger social ties than individuals with higher status. ${ }^{55}{ }^{57}$ One of the explanations of weak social networks among managers and engineers in the GAZEL cohort may be frequent geographical mobility.$^{58}$ Our measure of social networks included items regarding the frequency of visual contacts with family and friends that could be negatively associated with geographical distance. ${ }^{59}$ Research showing that educational achievement is predictive of relocating ${ }^{60}$ suggests that socioeconomic status is associated with geographical mobility in the French population at large. Lower social integration among women in high occupational groups is also partly explained by the fact that they are least likely to be married ( $68 \%$ of "managers and engineers", compared with $77 \%$ of "administrative associate professionals" and $74 \%$ of "foremen/technicians") —a finding typical not only of France but also other countries. ${ }^{6}$

Although more socially isolated, higher status men were least likely to report a lack of personal social support or dissatisfaction with their social relations. We did not find this to be the case among women. One interpretation is that the function of a social network varies across socioeconomic groups, as it does for men and women. ${ }^{2}$ For instance, members of lower status groups may be exposed to a greater number of adverse life events making them solicit their network's support. Our results differ from previous studies showing that French men who are unemployed are most likely to be socially isolated ${ }^{6364}$ and suggest that future research on the health effects of social networks should distinguish between working and non-working men and women.

\section{Gender effects}

We found that inadequate psychosocial work conditions and poor social relations had different effects on sickness absence rates among men and women. Overall both poor psychosocial conditions at work and insufficient social relations were more frequent among women. Psychosocial work factors had greater effects on men's rates of sick leave except for high psychological demands, which predicted the occurrence of short absences among women but not men. Social isolation and poor social support had an impact on men's, but not women's, long absences. The work and home environments of men and women, as well as their perceptions of psychosocial conditions, may vary. This is consistent with other studies of gender specific determinants of health. ${ }^{65}$ Furthermore, our findings suggest that the work environment is more important in determining men's health, which confirms the results of previous research evaluating the impact of control at work and at home with regard to mental health..$^{35}$

In our study the incidence rate of sickness absence, particularly of short duration, was higher among women than among men. Nevertheless the associations between the exposures of interest and this outcome did not vary with gender. It is possible that men are more vulnerable to the psychosocial work and home factors we studied. They may also be exposed to other deleterious risk factors that we did not account for. Furthermore, the subjective assessment of psychosocial work conditions and social relations may vary for men and women. In another study, currently under way, we are investigating the contribution of a broad range of factors to socioeconomic and gender differences in absenteeism in this population.

\section{Selection effects}

Our study may be prone to selection biases. GAZEL cohort participants are more likely to be married, healthy, and to occupy a higher professional status than EDF-GDF employees who refused to participate in the study in $1989 .{ }^{66} \mathrm{Job}$ characteristics and the range of social relations in this study may 


\section{Key points}

- Low job control, personal social support, and satisfaction with social relations independently predict increased rates of sickness absence over an extended period of follow up. Men are susceptible to poor social support at work; women to high psychological demands.

- Psychosocial work factors are associated with occupational status. The relation between social networks, personal social support, and satisfaction with social relations and socioeconomic status is complex.

- Women are more likely to be exposed to detrimental psychosocial work factors and poor social relations.

- The health effects of improvements in the psychosocial characteristics of the work and home environment should receive research attention. This will allow for the design of effective public health interventions in the field.

have been shifted in the non-exposed direction, reducing our probability of observing ill health. Consequently, our results may underestimate the absolute health effects of psychosocial exposures.

Self reports of psychosocial factors may be subject to a response bias. Unfortunately, there are no objective measures of the psychosocial work environment in this study. With regard to social relations we found that employees' perceptions of social support and satisfaction with social relations, rather than a structural measure of social networks, were predictive of sickness absence. We measured psychosocial characteristics in 1995 and social relations in 1994, assuming that these factors could be held constant over the duration of follow up. In this population of middle aged employees job characteristics are unlikely to have dramatically changed from 1995 to 2001. If subjects' social relations were modified during follow up, there is no indication that the resulting misclassification was differential. There is no reason to believe that the collection of exposure data at two points in time resulted in a systematic bias.

\section{Conclusions}

Our findings illustrate the importance of the work and social environments as determinants of sickness absence over an extended period of follow up. Members of lower occupational groups, and women in particular, are particularly at risk of suffering from a lack of job control and unsupportive social relations. This study adds to the body of evidence suggesting that the psychosocial environment should be a target for the prevention of ill health in working populations. From employers' perspective, this strategy could offer the advantage of significantly decreasing absenteeism and reducing the associated socioeconomic costs.

\section{ACKNOWLEDGEMENTS}

The authors wish to express their gratitude to all the volunteers of the GAZEL cohort, who made this study possible. Our thanks go to EDFGDF, especially to Ms A Chevalier (Service Général de Médecine de Contrôle), who provided the sick leave absence data, to the Service des Etudes Médicales, and to the GAZEL study team, in particular Isabelle Bugel, Sébastien Bonenfant, Jean-François Chastang, Alice Guéguen, and Marie Zins for their technical assistance.

\section{Authors' affiliations}

M Melchior, L F Berkman, Harvard School of Public Health, Department of Health and Social Behavior, Boston, USA

M Melchior, I Niedhammer, $\mathbf{M}$ Goldberg, INSERM, Unit 88, Hôpital

National de Saint-Maurice, Saint-Maurice, France

Funding: Maria Melchior is the recipient of the Chateaubriand Fellowship, awarded by the Office for Science and Technology of the Embassy of France in the United States.

Conflicts of interest: none.

\section{REFERENCES}

1 Marmot MG, Feeney A, Shipley M, et al. Sickness absence as a measure of health status and functionning: from the UK Whitehall II study. J Epidemiol Community Health 1995;49:24-30.

2 Kivimäki $M$, Sutinen R, Elovainio $M$, et al. Sickness absence in hospital physicians: 2-year follow-up study on determinants. Occup Environ Med 2001;58:361-6.

3 Kristensen TS. Sickness absence and work strain among Danish slaughterhouse workers: an analysis of absence from work regarded as coping behaviour. Soc Sci Med 1991;32:15-27.

4 Rael E, Stansfeld S, Shipley M, et al. Sickness absence in the Whitehall II study, London: the role of social support and material problems. J Epidemiol Community Health 1995;49:474-81.

5 Mastekaasa A. Parenthood, gender and sickness absence. Soc Sci Med 2000;50: 1827-42

6 Virtanen P, Nakari R, Ahonen $\mathrm{H}$, et al. Locality and habitus: the origins of sickness absence practices. Soc Sci Med 2000:50:27-39.

7 Knutsson A, Goine H. Occupation and unemployment rates as predictors of long-term sickness absence in two Swedish counties. Soc Sci Med 1998;47:25-31.

8 Chevalier A, Blanc C, Goldberg M. Réorganisation du travail et absentéisme pour raison médicale dans un Centre de distribution d'Electricité de France-Gaz de France. Arch Mal Prof 1990;51:235-43.

9 Kivimäki M, Vahtera J, Ferrie J, et al. Organisational downsizing and muscoskeletal problems in employees: a prospective study. Occup Environ Med 2001;58:811-17.

10 Prins R, Graaf D. Comparison of sickness absence in Belgian, German and Dutch firms. Br J Ind Med 1986;43:529-36.

11 Kivimäki M, Vahtera J, Thomson L, et al. Psychosocial factors predicting employee sickness absence during economic decline. J Appl Psychol 1997;82:858-72

12 Vahtera J, Kivimäki M, Pentti J, et al. Effect of change in psychosocial work environment on sickness absence: a seven-year follow-up of initially health employees. J Epidemiol Community Health 2000;54:484-93.

13 Luz J, Green M. Sickness absence from work-a critical review of the literature. Public Health Rev 1997;25:89-122.

14 Chevalier A, Goldberg M. L'absence au travail: indicateur social ou indicateur de santé? Sci Soc Santé 1992;X:47-65.

15 Schnall P, Lansbergis P, Baker D. Job strain and cardiovascular disease. Ann Rev Public Health 1994;15:381-41 1

16 Bongers $\mathbf{P}$, de Winter $C$, Kompier $M$, et al. Psychosocial factors at work and muscoskeletal disease. Scand J Work Environ Health 1993; 19:297-312.

17 Davis K, Heaney C. The relationship between psychosocial work characteristics and low back pain: underlying methodological issues. Clin Biomech 2000;15:389-406.

18 North F, Syme SL, Feeney A, et al. Psychosocial work environment and sickness absence among British civil servants: the Whitehall II study. Am J Public Health 1996;86:332-40.

19 Niedhammer I, Bugel I, Goldberg M, et al. Psychosocial factors at work and sickness absence in the Gazel cohort: a prospective study. Occup Environ Med 1998; 55:735-41.

20 Stansfeld SA, Fuhrer R, Shipley M, et al. Work characteristics predict psychiatric disorder: prospective results from the Whitehall II study. Occup Environ Med 1999;56:302-7.

21 Unden A. Social support at work and its relationship to absenteeism. Work Stress 1996;10:46-61.

22 Stansfeld SA, Bosma $\mathrm{H}$, Hemingway $\mathrm{H}$, et al. Psychosocial work characteristics and social support as predictors of SF-36 health functionning: the Whitehall II study. Psychosom Med 1998;60:247-55.

23 Niedhammer I, Goldberg M, Leclerc A, et al. Psychosocial factors at work and subsequent depressive symptoms in the Gazel cohort. Scand J Work Environ Health 1998;24:197-205

24 Theorell T, Ahlberg-Hulten G, Jodko M, et al. Influence of job strain and emotion on blood pressure in female hospital personnel during workhours. Scand J Work Environ Health 1993;19:313-18.

25 Green K, Johnson J. The effects of psychosocial work organization on patterns of cigarette smoking among male chemical plant employees. Am J Public Health 1990;80:1368-71.

26 Brisson C, Larocque B, Moisan J, et al. Psychosocial factors at work, smoking, sedentary behavior, and body mass index: a prevalence study among 6995 white collar workers. J Occup Environ Med 2000;42:40-6

27 Niedhammer I, Goldberg M, Leclerc A, et al. Psychosocial work environment and cardiovascular risk factors in an occupational cohort in France. J Epidemiol Community Health 1998;52:93-100.

28 Hemmingsson T, Lundberg I. Work control, work demands, and work social support in relation to alcoholism among young men. Alcohol Clin Exp Res 1998;22:921-7.

29 Boedeker W. Associations between workload and diseases rarely occurring in sickness absence data. J Occup Environ Med 2001;43:1081-8.

30 Virtanen $M$, Kivimäki $M$, Elovainio $M$, et al. Contingent employment, health, and sickness absence. Scand J Work Environ Health 2001;27:365-72.

31 House J, Landes K, Umberson D. Social relations and health. Science 1988;241:540-4

32 Berkman L, Glass T, Brissette I, et al. From social integration to health Durkheim in the new millenium. Soc Sci Med 2000;51:843-57.

33 Bourbonnais R, Mondor M. Job strain and sickness absence among nurses in the province of Québec. Am J Ind Med 2001;39:202. 
34 Stansfeld SA, Rael E, Head J, et al. Social support and psychiatric sickness absence: a prospective study of British civil servants. Psychol Med 1997;27:35-48.

35 Griffin JM, Fuhrer R, Stansfeld SA, et al. The importance of low control at work and home on depression and anxiety: do these effects vary by gender and social class? Soc Sci Med 2002;54:783-98.

36 Kivimäki M, Vahtera J, Thomson L, et al. Psychosocial factors predicting employee sickness absence during economic decline. J Appl Psychol 1997;82:858-72.

37 Marmot MG, Fuhrer R, Ettner SL, et al. Contribution of psychosocial factors to socio-economic differences in health. Milbank Q 1998 ; 76:403-48.

38 Stansfeld SA, Head J, Marmot MG. Explaining social class differences in depression and well-being. Soc Psychiatry Psychiatr Epidemiol 1998:33:1-9.

39 Melchior M, Berkman LF, Niedhammer l, et al. Social relations and self-reported health: a prospective analysis of the French Gazel cohort. Soc Sci Med (in press).

40 Goldberg M, Leclerc A, Chastang J, et al. Mise en place d'une cohorte épidémiologique à Electricité de France-Gaz de France: recrutement des volontaires. Rev Epidémiol Santé Publique 1990;38:265-8.

41 Goldberg M, Leclerc A, Chastang J, et al. Mise en place d'une cohorte épidémiologique à Electricité de France-Gaz de France: principales caractéristiques de l'échantillon. Rev Epidémiol Santé Publique $1990 \cdot 38: 378-80$.

42 Hensing G, Alexanderson K, Allebeck $P$, et al. How to measure sickness absence? Literature review and suggestion of five basic measures. Scand J Soc Med 1998;26: 133-44.

43 Karasek R, Theorell T. Healthy work: stress, productivity and the reconstruction of working life. New York, NY: Basic Books, 1990.

44 Johnson J, Hall E, Theorell T. Combined effects of job strain and social isolation on cardiovascular disease morbidity and mortality in a random sample of the Swedish male working population. Scand J Work Environ Health 1989:15:271-9.

45 Niedhammer I. Psychometric properties of the French version of the Karasek Job Content Questionnaire: a study of the scales of decision latitude, psychological demands, social support and physical demands. Int Arch Occup Environ Health 2002;75: 129-44.

46 Seeman TE, Berkman LF. Structural characteristics of social networks and their relationship with social support in the elderly: who provides support. Soc Sci Med 1988;26:737-49.

47 Berkman LF, Syme SL. Social networks, host resistance and mortality: a nine-year follow-up study of Alameda county residents. Am J Epidemiol 1979;109:186-204

48 Kawachi I, Colditz GA, Ascherio A, et al. A prospective study of social networks in relation to total mortality and cardiovascular disease in men in the USA. J Epidemiol Community Health 1996;50:245-51.

49 Marmot M, Feeney A, Shipley $M$, et al. Sickness absence as a measure of health status and functionning: from the UK Whitehall II study. J Epidemiol Community Health 1995;49:124-30.
50 North F, Syme SL, Feeney A, et al. Psychosocial work environment and sickness absence among British civil servants: the Whitehall II study. Am J Public Health 1996;86:332-40.

51 SAS Institute. SAS/STAT software: changes and enhancements through release 6.12. Cary: NC: SAS Institute, 1997.

52 Chevalier A, Souques M, Coing $F$, et al. Absenteism and mortality of workers exposed to electromagnetic fields in the French Electricity Company. Occup Med 1999:49:517-24.

53 Blank M, Diderchsen F. Short-term sick leave in Sweden: relationships with social circumstances, working conditions and gender. Scand J Soc Med 1995:23:265-72

54 Wallace R, Wallace D. Socioeconomic determinants of health: community marginalisation and the diffusion of disease and disorder in the United States. BMV 1997;314:1341-5.

55 Cattell V. Poor people, poor places, and poor health: the mediating role of social networks and social capital. Soc Sci Med 2001;52:1501-16.

56 Rosengren A, Orth-Gomer K, Wilhelmsen L. Socioeconomic differences in health indices, social networks and mortality among Swedish men. Scand J Soc Med 1998;26:272-80.

57 Kubzansky L, Berkman L, Glass T, et al. Is educational attainment associated with shared determinants of health in the elderly? Findings from the Mac Arthur studies of successful aging. Psychosom Med 1998;60:578-85

58 Luce D, Chastang J-F, Goldberg M, et al. Mobilité et santé: de la sociologie à l'épidémiologie? Sci Soc Santé 1987;5:225-54.

59 Rivière C-A. Le téléphone: un facteur d'intégration sociale. Econ Stat $2001 ; 5: 3-32$.

60 Julien P, Laganier J, Pougnard J. Les études supérieures: un motif de migration. INSEE Première 2001:813:1-3.

61 Tomiak M, Gentleman JF, Jette M. Health and gender differences between middle and senior managers in the Canadian public service. Soc Sci Med 1997:45: 1589-96.

62 Fuhrer R, Stansfeld S, Chemali J, et al. Gender, social relations and mental health: prospective findings from an occupational cohort (Whitehall II study). Soc Sci Med 1999;48:77-87.

63 Pan Ké Shon J-L. Vivre seul, sentiment de solitude et isolement relationnel. INSEE Première 1999;678:1-3.

64 Lhommeau B. Les allocataires du RMI: moins isolés au sens familial ef social que dans la statistique administrative. Econ Stat 2001;6/7:33-52.

65 Denton M, Walters V. Gender differences in structural and behavioral determinants of health: an analysis of the social production of health. Soc Sci Med 1999;48:1221-35.

66 Goldberg M, Chastang J-F, Leclerc A, et al. Socioeconomic, demographic, occupational and health factors associated with participation in a long-term epidemiological survey. A prospective study of the French Gazel cohort and its target population. Am J Epidemiol 2001;154:373-84. 